\title{
Detection of Acetyl-CoA Carboxylase (ACCase) Inhibitor Herbicides Resistance in Sterile Wild Oat (Avena sterilis L.) Using Agar Quick Test
}

\author{
Abdullatief Mohammed Abdurruhman, Sibel Uygur and Feyzullah Nezihi Uygur \\ Department of Plant Protection, Faculty of Agriculture, Çukurova University, Adana 1330, Turkey
}

\begin{abstract}
This study was conducted using seeds in Petri dish containing agar medium in order to determine acetyl-CoA carboxylase (ACCase) herbicides resistance (R) in Avena sterilis that was grown in wheat fields at Adana province, Turkey. Seeds were collected from one large suspected field, where clodinafop-propargyl (Aryloxyphenoxypropionate "FOPs") and pinoxaden (Phenylpyrazoline "DEN") have been applied for many years. Susceptible (S) population was collected from the road side on the same region. Agar media of concentration $14 \mathrm{~g} / \mathrm{L}$ was prepared and it was melted in microwave. Then the amount of $20 \mathrm{~mL}$ agar media was added into each Petri dish. Five seeds were placed on agar mediums containing discriminating dose of clodinafop and pinoxaden. Petri dishes were placed in growth incubator operating at $10^{\circ} \mathrm{C}$. After $15 \mathrm{~d}$, both radicle and hypocotyl length were measured. The percentage of germinated seed and dose-response curves were determined. At these different concentration levels, there were more than $50 \%$ of $\mathrm{R}$ and less than $40 \%$ of S seed germinated for pinoxaden. However, for clodinafop, more than $60 \%$ of R and less than $50 \%$ of S seeds were germinated. At higher concentration levels, the populations of resistant and susceptible were not germinated for both herbicides. The resistance value of $\mathrm{R}$ population was then compared with that of the $\mathrm{S}$ biotype. From the resistance index (RI), the population was more resistant to pinoxaden ( 7.43 for radicle and 2.47 for hypocotyl) than the clodinafop-propagyl (1.39 for radicle and 3.77 for hypocotyl). The method provided a simple, quick and cost effective way to identify ACCase herbicides resistance in most grass weeds.
\end{abstract}

Key words: Acetyl-CoA carboxylase, herbicides resistance, Avena sterilis L., clodinafop-propargyl, pinoxaden.

\section{Introduction}

Sterile wild oat (Avena sterilis L.) is an autogamous weed species. It possess an important economic menace to crop yields, because of their high spread germination and great degree of phenotypic differentiation, essential generative produce and in the absence of competition, A. sterilis being considered to produce large number of seeds, and ability of seed to remain in the soil seed bank [1-3]. Sterile wild oat has been found in Mediterranean climate zone, such as Southern Europe and Northern Africa [4]. It is the most habitual and intense species in the Adana province, Turkey, which is considered as one of the first cultivation areas [5]. In Adana province, $A$.

Corresponding author: Abdullatief Mohammed Abdurruhman, Ph.D. student, research field: weed science. sterilis was reported at $86 \%$ of the studied fields in the mid-1980s. In the early 1990s, however, sterile wild oats were found in almost all fields [6]. A. sterilis cause problems to other crops, such as lentil and onion, as they are cultivated in crop rotation with barley or wheat. A form of chemical weed control, such as herbicides has been used in Turkey since 1970s, however, the sterile wild oat plants survive and they were detected in the late 1990s. The economic thresholds for A. sterilis management with herbicides in Adana province were estimated 3-5 plants $/ \mathrm{m}^{2}$, depending on the crop variety [5]. The most importance herbicides to control this weed are ACCase-inhibiting herbicides, followed by acetolactate synthase (ALS) inhibiting herbicides [7]. Aryloxyphenoxypropionate (APP or FOPs) and phenylpyrazoline (DEN) are chemical-based 
herbicides that inhibit ACCase, by catalyzing the first step of fatty acid biosynthesis. The most effective ACCase-inhibiting herbicide against grass weed is safener that enhances the selectivity of herbicide metabolism in grass crops [8]. The consistent usage of herbicides, such as clodinafop-propagyl and pinoxaden has widely detected the resistances in a number of weed species. The herbicide resistance of 48 grass weed species has been documented [9]. In Turkey, the major grass weeds that are resistant to ACCase are sterile wild oat (A. sterilis L.), black-grass (Alopecurus myosuroides Hudson), shortspike canarygrass (Phalaris brachystachys Link.), early watergrass (Echinochloa oryzoides (Ard.)), barnyardgrass (Echinochloa crus-galli var. crus-galli L.) and wild oat (Avena fatua L.) [9]. Some of $A$. sterilis are extremely resistant to diclofop-methyl and moderate resistant to other APP herbicides [10]. Meanwhile, other A. sterilis biotypes are low resistant to cyclohexanedione (CHD) herbicides [11]. Many of this species exhibit cross-resistance to APP and CHD, whereas other research [12] proved resistance of $A$. sterilis includes target or/and non-target site mechanisms. Target-site resistance comes from variations of the gene encoding resistant ACCase to ACCase-inhibiting herbicides [13]. Non-target-site resistance results from lessening penetration that reduced translocation $[14,15]$. Non-target-site can confer resistance to ACCase and other herbicides have dissimilar modes of action [8]. Various methods have been developed in order to determine the ACCase resistance in grass weed. Field analyses were conducted for locations where resistance was suspected [16]. Also, experiments were performed for simple plant [17], seedling [18], seed [19] or pollen bioassays [20], which were carried out under controlled conditions in the glasshouse or in growth cabinets. Alternative methods used to detect herbicide resistance in laboratory were based on enzyme [21, 22], DNA [23], the analysis of known mutations using cleaved amplified polymorphic sequence (CAPS) [24] and real-time quantitative PCR $[25,26]$. The whole plant assay is the main common method for detecting resistance $[27,28]$.

Therefore, the objective of current research was to detect the resistance levels of ACCase inhibitor herbicides (e.g., clodinafop-propargyl and pinoxaden) in A. sterilis population, which was collected and treated with discriminating dose of herbicides in agar medium under controlled condition. Both susceptible $(\mathrm{S})$ and resistance $(\mathrm{R})$ populations are compared and the herbicide efficacy is measured by germination percent, as well as hypocotyl and radicle length.

\section{Materials and Methods}

\subsection{Seeds Sample Collection}

In May-June 2016 (before harvesting the wheat), A. sterilis seed samples were collected from suspected field in Adana province ( $37^{\circ} 28^{\prime} 14.52^{\prime \prime} \mathrm{N}, 35^{\circ} 45^{\prime} 59.82^{\prime \prime}$ E). After receiving complaints about the deteriorating effectiveness of ACCase inhibitor herbicide, suspected samples were collected from many sites of the farm. Susceptible standard population were collected from the same region surrounding the field (served as control). Collected seeds were air-dried and kept in a cold room maintained at $4{ }^{\circ} \mathrm{C}$ for experimental purpose. Two commercial herbicides were used to determine the response of $A$. sterilis population as in Table 1.

\subsection{Preparation of Agar Culture}

Plant agar of 13-14 $\mathrm{g}$ was mixed with $1 \mathrm{~L}$ distilled water. The mixture was liquefied in a microwave and

Table 1 Herbicides preperations used in the experiment.

\begin{tabular}{lll}
\hline Herbicides & Concent. (g a.i./L) & Recommended dose (g a.i./ha) \\
\hline Clodinafopl-propargyl & 240 & 48 \\
Pinoxaden & 45 & 45 \\
\hline
\end{tabular}


allowed to coolness to approximately $35-40{ }^{\circ} \mathrm{C}$ before the commercial herbicides solution were added into Petri dishes.

\subsection{Seed Germination Experiment}

A total of $20 \mathrm{~mL}$ agar was poured into glass Petri dishes of $9 \mathrm{~cm}$ diameter. The population was treated at a large range of concentrations, i.e., $0,0.16,0.33,0.66$, 1.32, 2.64 and $5.28 \mathrm{~mL} / \mathrm{L}$ for clodinafop-propargyl and $0,0.75,1.5,3,6,12$ and $24 \mathrm{~mL} / \mathrm{L}$ for pinoxaden. Then, of each concentration the herbicide solution of $270 \mu \mathrm{L}$ was added to each Petri dishes. Five seeds were placed on agar medium in each Petri dishes (six replicates). All Petri dishes were incubed in refregator at $10{ }^{\circ} \mathrm{C}$. After $15 \mathrm{~d}$, the percentage of seeds growth was recorded, and the lengths of hypocotyl and radicle were measured. The experiment was repeated two times.

\subsection{Data Analysis}

The data were analysed using non-linear regression of ANOVA. The concentration of herbicide causing $50 \%$ of growth reduction $\left(E D_{50}\right)$ was studied using four parameters log-logistic curve [29].

$$
y=c+\frac{d-c}{1+\exp \left[b\left(\log (x)-\log \left(E D_{50}\right)\right)\right]}
$$

where, $y$ was hypocotyl or radicle length, $c$ was lower limit, $d$ was upper limit, $b$ was slope of the curve and $E D_{50}$ was dose giving $50 \%$ growth reduction. Resistance index (RI) was indicated by $E D_{50}$, i.e., the ratio of resistant to susceptible population.

\section{Results and Discussion}

The agar-based medium was found to be suitable for growing sterile wild oat seeds. Depending on seedlings radicle length in agar medium, the fitted RI (Table 2) for pinoxaden and clodinafop-propargyl were 7.43 and 1.39 , respectively.

Hypocotyl elongations were estimated at 2.47 for pinoxaden and 3.77 for clodinafop-propargyl. Also, the results showed that sensitive population of clodinafop-propargyl between $1.8 \mu \mathrm{M}$ and $3.6 \mu \mathrm{M}$ and pinoxaden below $6.00 \mu \mathrm{M}$ were killed (Table 3). As expected, at least $24.8 \mu \mathrm{M}$ and $14.4 \mu \mathrm{M}$ of ACCase herbicides were needed to kill all standard sensitive populations of pinoxaden and clodinafop-propargyl, respectively. In each Petri dish, seeds were germinated within pinoxaden and clodinafop solutions. Herbicide inhibits radicle elongation, radicle swelling and hypocotyl growth.

Different responses were observed for various herbicide doses in the assay (Fig. 1), showing that the population was more resistant to clodinafop instead of pinoxaden. By increasing the rates of clodinafop and pinoxaden, the population had shorter hypocotyl and radicles as compared to the susceptible control.

Depending on dose-response curves of experiments for susceptible and resistant population, the effect of pinoxaden on hypocotyl was more prominent than that on radicle (Fig. 2). Meanwhile, the effect of clodinafop-propargyl on hypocotyl was more significant than that on radicle (Fig. 3).

In cases involving low concentration levels of both herbicides, a very short radicle was still observed. The hypocotyls and radicle lengths of resistance and susceptible populations were significantly different from those of the untreated control population. The effective control of A. sterilis in wheat mainly depends on ACCase and ALS inhibitor herbicides. Current diagnostic test employs post herbicide treatments,

Table 2 Parameters of dose response curve fitted on clodinafop-propargyl and pinoxaden from assay data.

\begin{tabular}{|c|c|c|c|c|c|c|}
\hline & \multicolumn{3}{|c|}{ Clodinafop-propargyl (48 g a.i./ha) } & \multicolumn{3}{|c|}{ Pinoxaden (45 g a.i./ha) } \\
\hline & \multicolumn{2}{|c|}{$\mathrm{ED}_{50}$} & \multirow{2}{*}{$\mathrm{RI}(\mathrm{R} / \mathrm{S}$ ratio) } & \multicolumn{2}{|c|}{$\mathrm{ED}_{50}$} & \multirow{2}{*}{$\mathrm{RI}(\mathrm{R} / \mathrm{S}$ ratio $)$} \\
\hline & $\mathrm{R}$ & $\mathrm{S}$ & & $\mathrm{R}$ & $\mathrm{S}$ & \\
\hline Hypocotyl & $75.56 \pm 0.16$ & $20.04 \pm 4.65$ & 3.77 & $320.70 \pm 37.12$ & $129.50 \pm 59.27$ & 2.47 \\
\hline Radicle & $40.32 \pm 37.12$ & $28.98 \pm 14.86$ & 1.39 & $601.19 \pm 179.9$ & $80.86 \pm 11.98$ & 7.43 \\
\hline
\end{tabular}



in Sterile Wild Oat (Avena sterilis L.) Using Agar Quick Test

Table 3 Percentage of survival of resistance (R) and susceptible (S) sterile wild oat phenotype surviving exposure to clodinafop-propargyl (a) and pinoxaden (b) in agar medium, calculated from hypocotyl length data.

\begin{tabular}{llllllll}
\hline (a) Clodinafop-propargyl exposure \\
\hline \multicolumn{7}{l}{} \\
\hline & 0 & 0.45 & 0.90 & 1.80 & 3.60 & 7.20 & 14.40 \\
Resistant & 100 & 93 & 85 & 76 & 48 & 12 & 0 \\
Susceptible & 100 & 90 & 75 & 45 & 33 & 9 & 0 \\
$p$-value & $* * *$ & $* * *$ & $* * *$ & $* *$ & $* *$ & NS & NS \\
\hline
\end{tabular}

(b) Pinoxaden exposure

\begin{tabular}{llllllll}
\hline & \multicolumn{7}{c}{ Agar medium $^{\mathrm{d}}(\mu \mathrm{M})$} \\
\hline & 0 & 0.75 & 1.50 & 3 & 6 & 12 & 24 \\
Resistant & 80 & 60 & 57 & 30 & 23 & 3 & 0 \\
Susceptible & 80 & 67 & 50 & 22 & 14 & 0 & 0 \\
$p$-value & $* * *$ & $* * *$ & $* *$ & $*$ & $*$ & $*$ & NS \\
\hline
\end{tabular}

${ }^{\mathrm{c}}$ Exposure to clodinafop-propargyl in agar medium with different concentrations; ${ }^{\mathrm{d}}$ Exposure to pinoxaden in agar medium with different concentrations.

$* * *, * *, *$ and NS represent $p \leq 0.0001, p \leq 0.001, p \leq 0.05$ and non-significant, respectively.

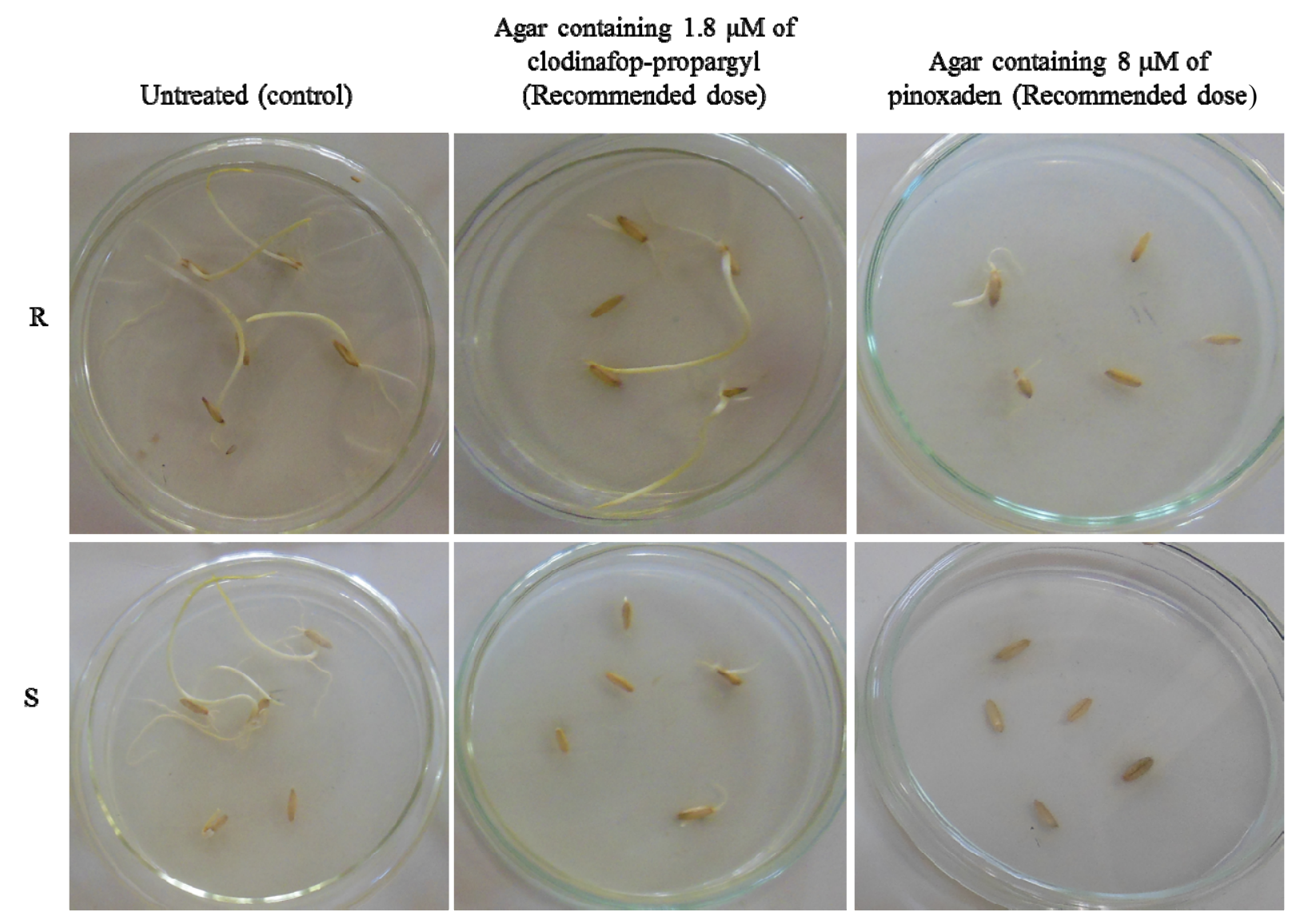

Fig. 1 Differentiation between resistant $(\mathrm{R})$ and susceptible $(\mathrm{S})$ populations of $A$. sterilis in agar medium containing herbicide. 

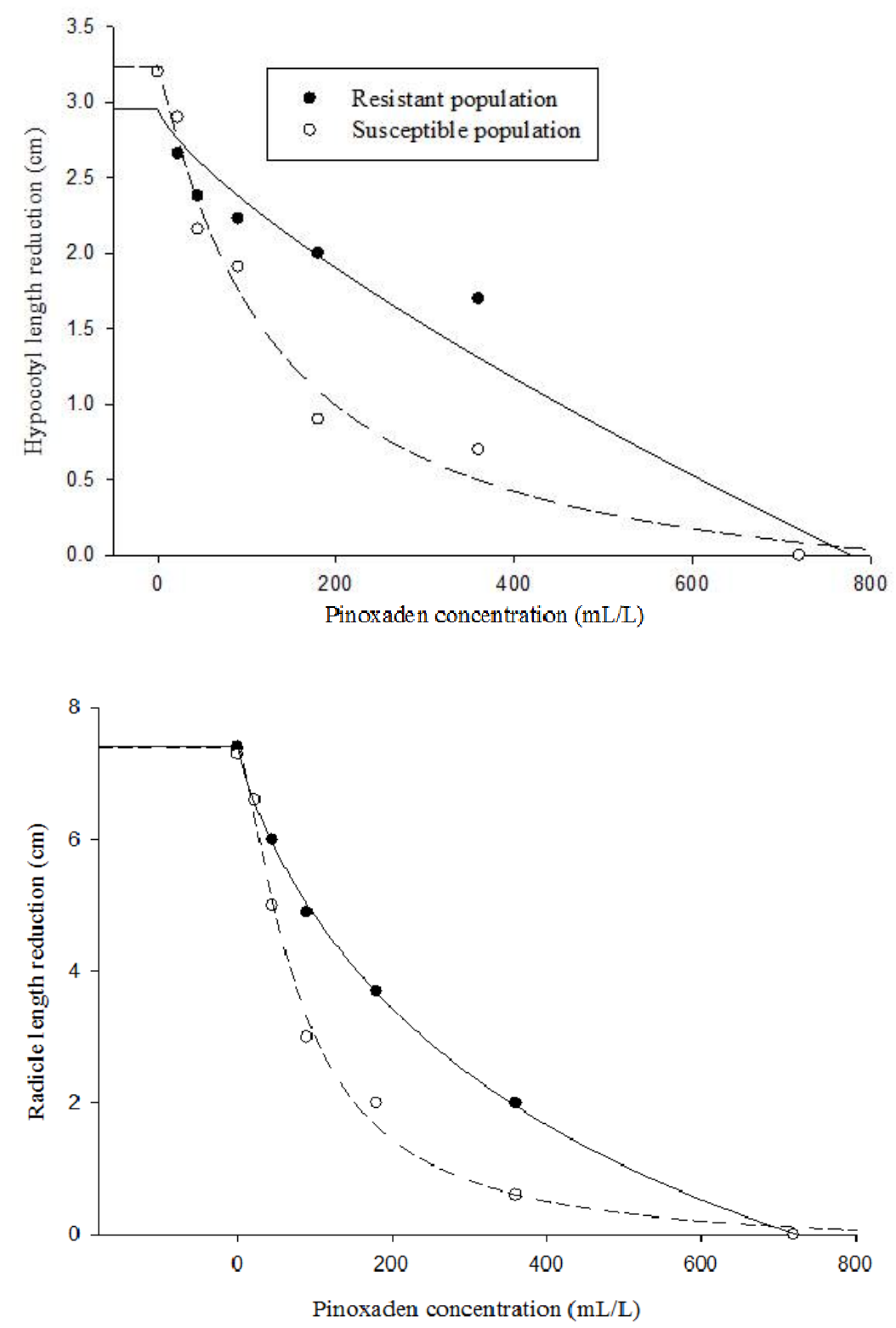

Fig. 2 Dose-response curves of experiments for susceptible (S) and resistant (R) population treated with pinoxaden.

such as pot assay [27], Syngenta quick assay using agar [17], germinate seeds Petri dishes [19] and pollen assay [20]. In Petri dish experiments involving agar medium, the lengths of hypocotyl and radicle were decreased as the concentrations of pinoxaden and clodinafop increased. However, radicles of susceptible and resistance populations were more sensitive to pinoxaden instead of hypocotyl. Correspondently, it has been noticed that MCPA (auxinic) herbicide has effect on radicle of seedling of Brasica napus [30]. This study showed that the Petri dish assay performed that using agar medium could reliably determine the ACCase herbicide resistance in A. sterilis. Quick test using seeds has been mainly utilized for determining resistances to glyphosate [31] and ACCase inhibition herbicides [32]. Depending on various pre-determined target and non-target site resistant in A. sterilis and Lolium spp. populations and three commonly used herbicides, the quick assay using agar medium correlates properly with the greenhouse pot test [33]. Similar research was done by Brosnan et al. [34], he found that the quick test using agar medium can be 

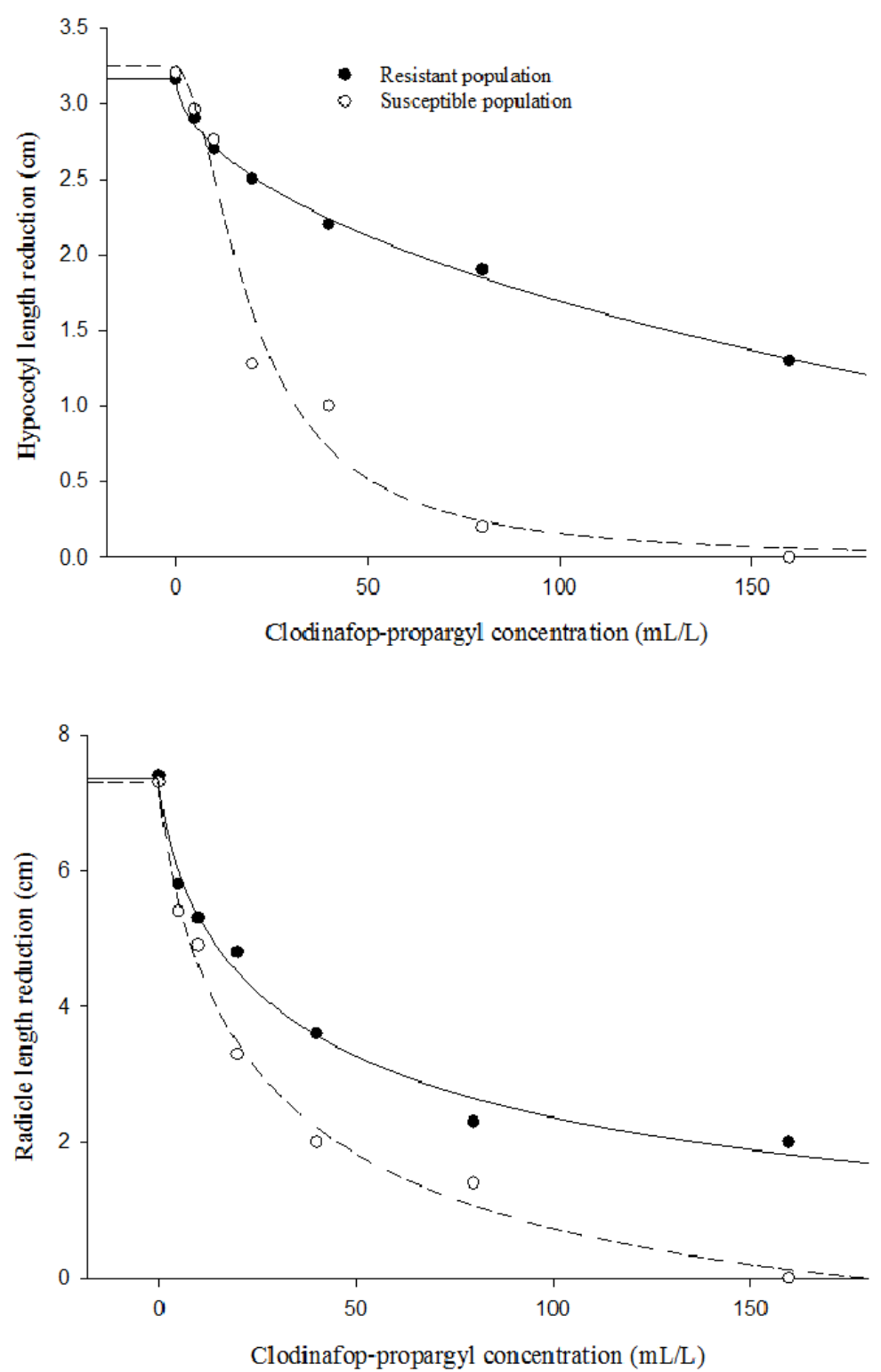

Fig. 3 Dose-response curves of experiments for susceptible (S) and resistant (R) population treated with clodinafop-propargyl.

used to determine the resistance of 5-enolpyruvylshikimate-3-phosphate (EPSP) and ALS inhibitor herbicides in Poa annua in less than two weeks. Kaundun et al. [35] described a simple, early-season experiment for detecting glyphosate resistance in monocots and dicots weed, he transplanted suspected seedlings alongside known sensitive and resistant standards into agar containing a range rate of herbicide and estimated the percentage survival species after $14 \mathrm{~d}$ of plating. Overall, the results of current experiment showed that resistance to ACCase herbicides (post and pre-emergence) can be detected using seed of grass weeds in agar medium.

\section{Conclusions}

In general, the present study revealed that resistance in A. sterilis population in suspected wheat field has occurred, evolved and established. Advantages of this 

in Sterile Wild Oat (Avena sterilis L.) Using Agar Quick Test

method are the rapid results, simple, quick, cost effective and the much lower need for working materials and human efforts. The method also can be used with other grass weed species. Under the temperature $10{ }^{\circ} \mathrm{C}$, it described the best condition to germinate A. sterilis biotype in incubation. However, it is believed that further studies of other population of the same species will yield such cross or multiple resistance mechanisms. Finally, it advised the farmers to manage herbicides resistance by applying crop rotation and consequently, different weed management methods would be the best way to control resistant A. sterilis in this region.

\section{Acknowledgments}

This work is funded by Scientific Research Projects Unit (FDK-2017-8186) of Cukurova University.

\section{References}

[1] Owen, M. J., and Powles, S. B. 2009. "Distribution and Frequency of Herbicide-Resistant Wild Oat (Avena spp.) across the Western Australian Grain Belt." Crop \& Pasture Science 60 (1): 25-31.

[2] Travlos, I. S., and Giannopolitis, C. N. 2010. "Assessment of Distribution and Diversity of Avena sterilis L. and Avena fatua L. in Cereal Crops of Greece Based on a Three-Year Survey and Selected Morphological Traits." Genetic Resources and Crop Evolution 57 (3): 337-41.

[3] Travlos, I. S. 2013. "Competition between ACCase-Inhibitor Resistant and Susceptible Sterile Wild Oat (Avena sterilis) Biotypes." Weed Science 61 (1): 26-31.

[4] Fernandez-Moreno, P. T., Alcantara-de la Cruz, R., Cruz-Hipólito, H. E., Rojano-Delgado, A. M., Travlos, I., and De Prado, R. 2016. "Non-target Site Tolerance Mechanisms Describe Tolerance to Glyphosate in Avena sterilis." Frontiers in Plant Science 7: 1220.

[5] Kadioglu, I. 1989. Studies on Wild Oat (Avena spp.) Species and Their Growth Characteristics, Competition between Wild Oats and Wheat, and Control Possibilities in Wheat Fields of Cukurova Region, Adana. Plant Protection Research Institute, Ministry of Agriculture, 128.

[6] Uygur, F. N., Kadioglu, I., and Boz, O. 1993. "Changes in Density of Wild Oat (Avena sterilis L.) in Wheat Fields of the Cukurova Region during Last 10 Years." In
Proceedings of the First Weed Science Congress, Turkey.

[7] Travlos, I. S., Giannopolitis, C. N., and Economou, G. 2011. "Diclofop Resistance in Sterile Wild Oat (Avena sterilis L.) in Wheat Fields in Greece and Its Management by Other Post-emergence Herbicides." Crop Protection 30 (11): 1449-54.

[8] Délye, C., Menchari, Y., and Michel, S. 2005. "A Single Polymerase Chain Reaction-Based Assay for Simultaneous Detection of Two Mutations Conferring Resistance to Tubulin-Binding Herbicides in Setaria viridis." Weed Research 45 (3): 228-35.

[9] Heap, I. 2017. "The International Survey of Herbicide Resistant Weeds." Accessed September 11, 2017. http://www.weedscience.org/Account/FAQ.aspx\#cite.

[10] Powles, S. B., and Yu, Q. 2010. "Evolution in Action: Plants Resistant to Herbicides." Annual Review of Plant Biology 61: 317-47.

[11] Beckie, H. J. 2006. "Herbicide-Resistant Weeds: Management Tactics and Practices." Weed Technology 20 (3): 793-814.

[12] Valverde, B. E. 1996. "Management of Herbicide Resistant Weeds in Latin America: The Case of Propanil-Resistant Echinochloa colona in Rice." In Proceedings of the Second International Weed Control Congress, Volume 1-4, 415-20.

[13] Papapanagiotou, A. P., Paresidou, M. I., Kaloumenos, N. S., and Eleftherohorinos, I. G. 2015. "ACCase Mutations in Avena sterilis Populations and Their Impact on Plant Fitness." Pesticide Biochemistry and Physiology 123: 40-8.

[14] Preston, C. 2004. "Herbicide Resistance in Weeds Endowed by Enhanced Detoxification: Complications for Management." Weed Science 52 (3): 448-53.

[15] De Prado, R. A., and Franco, A. R. 2004. "Cross-resistance and Herbicide Metabolism in Grass Weeds in Europe: Biochemical and Physiological Aspects." Weed Science 52 (3): 441-7.

[16] Moss, S. 1995. "Techniques for Determining Herbicide Resistance." In Proceeding of BCPC Crop Protection Conference: Weeds. Brighton, UK.

[17] Boutsalis, P. 2001. "Syngenta Quick-Test: A Rapid Whole-Plant Test for Herbicide Resistance." Weed Technology 15 (2): 257-63.

[18] Letouzé, A., and Gasquez, J. 1999. “A Rapid Reliable Test for Screening Aryloxyphenoxy-Propionic Acid Resistance within Alopecurus myosuroides and Lolium spp. Populations." Weed Research 39 (1): 37-48.

[19] Bourgeois, L., Kenkel, N. C., and Morrison, I. N. 1997. "Characterization of Cross-resistance Patterns in Acetyl-CoA Carboxylase Inhibitor Resistant Wild Oat (Avena fatua)." Weed Science 45 (6): 750-5.

[20] Letouzé, A., and Gasquez, J. 2000. “A Pollen Test to 

in Sterile Wild Oat (Avena sterilis L.) Using Agar Quick Test

Detect ACCase Target-Site Resistance within Alopecurus myosuroides Populations." Weed Research 40 (2): 151-62.

[21] Yang, C. H., Dong, L. Y., Li, J., and Moss, S. R. 2007. "Identification of Japanese Foxtail (Alopecurus japonicus) Resistant to Haloxyfop Using Three Different Assay Techniques.” Weed Science 55 (6): 537-40.

[22] Marshall, R., and Moss, S. R. 2008. "Characterisation and Molecular Basis of ALS Inhibitor Resistance in the Grass Weed Alopecurus myosuroides." Weed Research 48 (5): 439-47.

[23] Delye, C., Matejicek, A., and Gasquez, J. 2002. "PCR-Based Detection of Resistance to Acetyl-CoA Carboxylase-Inhibiting Herbicides in Black-Grass (Alopecurus myosuroides Huds) and Ryegrass (Lolium rigidum Gaud)." Pest Management Science 58 (5): 474-8.

[24] Kaundun, S. S., and Windass, J. D. 2006. "Derived Cleaved Amplified Polymorphic Sequence, a Simple Method to Detect a Key Point Mutation Conferring Acetyl CoA Carboxylase Inhibitor Herbicide Resistance in Grass Weeds." Weed Research 46 (1): 34-9.

[25] Kaundun, S. S., Cleere, S. M., Stanger, C. P., Burbidge, J. M., and Windass, J. D. 2006. "Real-Time Quantitative PCR Assays for Quantification of L1781 ACCase Inhibitor Resistance Allele in Leaf and Seed Pools of Lolium Populations." Pest Management Science 62 (11): 1082-91.

[26] Délye, C., Boucansaud, K., Pernin, F., and Le Corre, V. 2009. "Variation in the Gene Encoding Acetolactate-Synthase in Lolium Species and Proactive Detection of Mutant, Herbicide-Resistant Alleles." Weed Research 49 (3): 326-36.

[27] Moss, S. R., Albertini, A., Arlt, K., Blair, A., Collings, L., Bulcke, R., Eelen, H., Claude, J. P., Cordingley, M., Murfitt, R., Gasquez, J., Vacher, C., Goodliffe, P., Cranstone, K., Kudsk, P., Mathiassen, S., De Prado, R., Prosch, D., Rubin, B., Schmidt, O., Walter, H., Thuerwaechter, F., Howard, S., Turner, M., Waelder, L., and Cornes, D. 1998. "Screening for Herbicide Resistance in Black-Grass (Alopecurus myosuroides): A 'Ring' Test." In Proceedings of the 50th International Symposium on Crop Protection, 671-9.

[28] Beckie, H. J., Heap, I. M., Smeda, R. J., and Hall, L. M. 2000. "Screening for Herbicide Resistance in Weeds." Weed Technology 14 (2): 428-45.

[29] Seefeldt, S. S., Jensen, J. E., and Fuerst, E. P. 1995. "Log-Logistic Analysis of Herbicide Dose-Response Relationships." Weed Technology 9 (2): 218-27.

[30] Polit, J. T., Praczyk, T., Pernak, J., Sobiech, L., Jakubiak, E., and Skrzypczak, G. 2014. "Inhibition of Germination and Early Growth of Rape Seed (Brassica napus L.) by MCPA in Anionic and Ester Form." Acta Physiologiae Plantarum 36 (3): 699-711.

[31] Perez, A., and Kogan, M. 2003. "Glyphosate-Resistant Lolium multiflorum in Chilean Orchards." Weed Research 43 (1): 12-9.

[32] Tal, A., Kotoula-Syka, E., and Rubin, B. 2000. "Seed-Bioassay to Detect Grass Weeds Resistant to Acetyl Coenzyme A Carboxylase Inhibiting Herbicides." Crop Protection 19 (7): 467-72.

[33] Kaundun, S. S., Hutchings, S. J., Dale, R. P., Bailly, G. C., and Glanfield, P. 2011. "Syngenta 'RISQ' Test: A Novel In-season Method for Detecting Resistance to Post-emergence ACCase and ALS Inhibitor Herbicides in Grass Weeds." Weed Research 51 (3): 284-93.

[34] Brosnan, J. T., Vargas, J. J., Reasor, E. H., Viggiani, R., Breeden, G. K., and Zobel, J. M. 2017. "A Diagnostic Assay to Detect Herbicide Resistance in Annual Bluegrass (Роa апnua)." Weed Technology 31 (4): 609-16.

[35] Kaundun, S. S., Hutchings, S. J., Harris, S. C., Jackson, L. V., Shashi-Kiran, R., Dale, R. P., and Mclndoe, E. A. 2014. "Simple In-season Bioassay for Detecting Glyphosate Resistance in Grass and Broadleaf Weeds Prior to Herbicide Application in the Field." Weed Science 62 (4): 597-607. 